\title{
PORTAL OF SECURITY AND SAFETY ENGINEERING AS A TOOL TO INCREASE THE SUSTAINABLE DEVELOPMENT OF HIGHER EDUCATION IN SECURITY IN THE EUROPEAN UNION AND BEYOND
}

\begin{abstract}
In this article we describe a project "Competency Based e-Portal of Security and Safety Engineering" - eSEC portal approved by The Education, Audio-visual and Culture Executive Agency (EACEA), developed in the period between 10/2009 and 10/2012. The eSEC portal is one of 10 centralised multilateral projects approved in 2009 by EACEA and only one with the University of Zilina as a coordinator, with total budget 356.138 Euros. The EACEA is responsible for the management of certain elements of the EU's programs in the fields of education and culture. The idea for the eSEC project originated from the demand to increase the quality of education in the field of security and safety. One of the key problems of the education is disparity between the knowledge received from educational institutions and the practical requirements. It is necessary to redefine how students are prepared for the challenges of the labour market: identifying competencies that are currently in demand and how it would be possible to link the educational systems of various institutions more efficiently. The aim of the eSEC project was to develop the competencies of students, teachers, researchers and professionals working in the field of security and safety, within the EU and the world. To achieve these objectives, an electronic portal was developed at www.esecportal.eu. The portal was launched in May 2012, hopefully starting the way to become an established and well known Internet portal on the security and safety education.
\end{abstract}

Keywords: Competency Based e-Portal, Security Education, eSEC.

\section{Introduction}

The eSEC project originated from the identified need to increase the quality of education in the field of security. Based on experiences from eastern and middle Europe, one of the key problems of the education is disparity between the knowledge received from educational institutions and the practical requirements. That is the reason why it is necessary to focus more on the way in which the participants of Lifelong Learning Programs (LLP) can be prepared for the challenges which emerge from the labour market, which competencies are required and how it would be possible to link the educational systems of various institutions more efficiently. Therefore, the aim of this project was to develop and increase the competencies of students, teachers, research personnel and professionals from EU countries who work in the field of security.

To achieve the project's objectives, an electronic portal eSEC was developed. The portal is intended to support its users in acquiring new competences. One of practical contributions of the eSEC is ability to define individualised study plans that may exploit the available exchange programmes offered by European universities and consequently to obtain competences in practice, wherever it is mostly suitable. The eSEC portal also provides information on the availability of current grants and studentships that are consistent with the chosen study plan and this information are provided to the user in an individualised form (also see [1] and [2]).

Since the eSEC users are intended to be mainly students, teachers, academics, and professionals with an interest in the field of security engineering, eSEC creates a link between the educational providers and the professional community for whole of EU.

\section{Portal - outcomes and results}

The eSEC portal consists of several modules which reflect the requirements of the stated partial objectives as follows (see Fig. 3):

Main Modules:

- Competency Based Creation of the Curriculum,

- Subjects,

- Scholarships Agencies,

- Glossary of Terms,

- Blogs,

\footnotetext{
* Tomas Lovecek ${ }^{1}$, Jozef Ristvej ${ }^{2}$, Katarina Kampova ${ }^{1}$, Juraj Vaculík ${ }^{1}$, Roberto Gamboa ${ }^{3}$, Adam Zagorecki ${ }^{4}$

${ }^{1}$ Department of Security Management, University of Zilina, Slovakia, E-mail: Tomas.Lovecek@fsi.uniza.sk

${ }^{2}$ Department of Crisis Management, University of Zilina, Slovakia

${ }^{3}$ Institute Polytechnic of Leiria, GIRM, ESTM, Professor Coordenador, Peniche, Portugal

${ }^{4}$ Cranfield University, Defence Academy of the United Kingdom, Senior Research Fellow, Shrivenham, United Kingdom
} 
- Forum,

- Resources,

- Student Projects,

- Calendar of Events,

- Labour Market,

- The European Journal of Security and Safety,

Other parts:

- Comments and Suggestions,

- Web Search,

- Project Partners.

Module Competency Based Creation of the Curriculum is the main module in the framework in which the users can choose the required competences that they wish to acquire in the areas of security and safety. The module provides a space for creating a study plan which may include various programmes, subjects, seminars and actions organised at the EU universities. This module also provides information about available scholarship programmess or grants that are related to the created study plan.

The Module Subject is designed to provide study subjects and study programmes focused on the problems of security and safety, offered by the European higher education institutions. Once a user is logged in, it provides customised offer based on the user's country highlighting local offers in the first place.

The Module Scholarship Agencies provides the users with information about scholarship programmes.

Module Glossary of Terms allows browsing an electronic dictionary of terms in the twelve defined fields of security and safety. Currently it consists more than 500 terms in 6 languages.

The "Blogs about Security and Safety" and "Forum" modules are designed to create a space for communication among project stakeholders and for publishing ideas related to the security and safety.

Module Resources is focused on innovative methods in education supporting creativity and active approach to education and training in the field of security and safety. It enables the stakeholders to share audio-visual presentations, lectures, field trips, practical workshops, measurements and other sources.

Module Student Projects provides tools for publishing and comparing students' works. It is intended to contribute to a deeper perception of the solved problems by the students. It is a space where the individual student can share the already acquired knowledge with other students or professionals.

Module Labour Market provides job offers in the field of security and safety within Europe. It allows for publishing professional CVs of the job applicants.

The Module Calendar of Events enables the portal users to know about the prepared events related to security and safety, mainly in the EU framework.
Last but not least, from the point of view of the project goal, is the module European Journal of Security and Safety (EJSS $\mathrm{http}: / /$ www.esecportal.eu/journal). EJSS is a new online European scientific journal, primary source of peer-reviewed research articles in all fields connected with security and safety. EJSS publishes peer-reviewed research articles, book reviews, news and communications, opinions from researchers and practitioners. The EJSS has ISSN 1338-6131 and several papers were already published. For details see Fig. 4.

The eSEC portal's goal is not only to collect all content in the field of security and safety but it is intended to provide links to other Internet sources related to the scope of interest. The Module Web Search serves this purpose. The user has an option, based on the entered competence, to browse and search in the databases, e.g. Open iCoper Content Space, Scientia or Google Scholar.

These elements of the portal (modules and parts) bring significant improvement for students' learning process and the users can benefit in both academically and later professionally. Students have opportunity to compare study programmes and requirements at different institutions, in scientific and professional environment. Teachers are able to get feedback from professionals, colleagues and students. In longer perspective the eSEC portal is expected to contribute to the users' attractiveness at the labour market. It should be achieved by directly highlighting competencies required by employers and matching them with the opportunities available for students on the portal and that may not be part of the local educational system (for more also see [3]).

Educational institutions can offer their courses and capabilities to the target groups, whereas, commercial and government organisations can provide the contents for individual modules (documents, articles, blogs, etc.) and therefore affect the curricula. At the same time these organisations have a possibility opportunity to obtain and improve their own expertise and training (for more also see [4] and [5]).

Figure 1 shows the first version of the portal at the beginning of the project. Figure 2 shows the beta version of the portal. The beta version was used just for the testing. Figure 4 is the final version of the eSEC portal. Figure 5 presents the logo of eSEC portal and the project. The link of the portal follows Fig. 5.

In the first part of the eSEC project the main focus was on learning the best practices in the area of portal development and competencies in areas of security. Several documents were produced by the consortium to prepare the grounds for the future eSEC portal. At that stage of the project several outcomes and results were produced: European Basic Security and Safety Glossary of Terms including 500 terms from the field of security and safety. The glossary was created within the frame of the Competency Based e-portal of Security and Safety Engineering project (www.esecportal.eu). The glossary was translated into six languages (Czech, English, French, Italian, Portuguese and Slovak).

One of the outputs of the project was preparation of the eSEC Best Practices conference in Zlin (http://esec.utb.cz/), on 18 March 


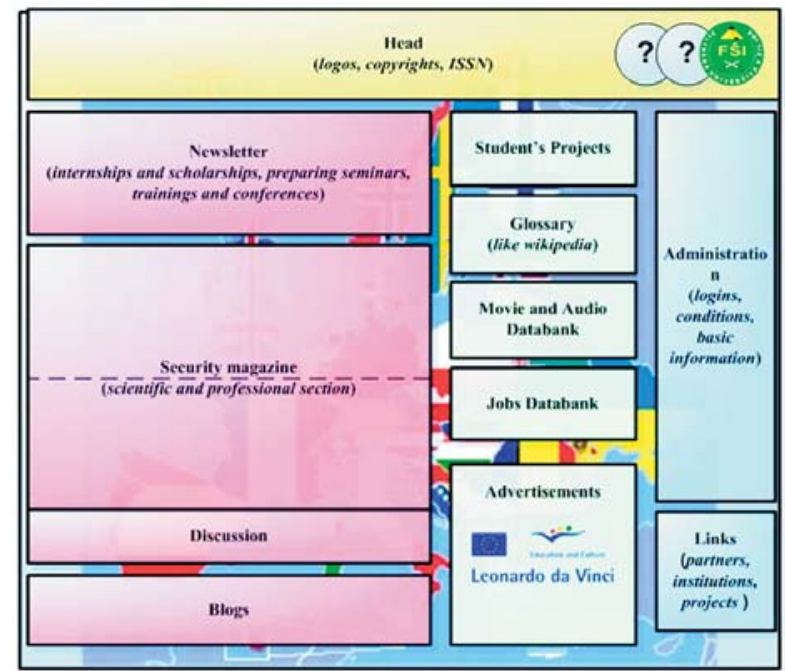

Fig. 1 eSEC Portal Structure, first idea

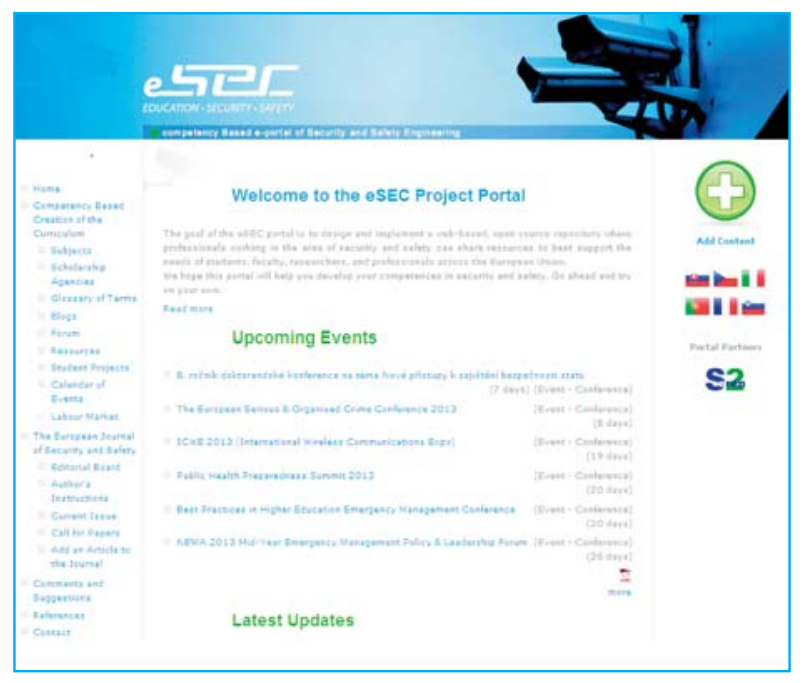

Fig. 3 Final version of the eSEC Portal

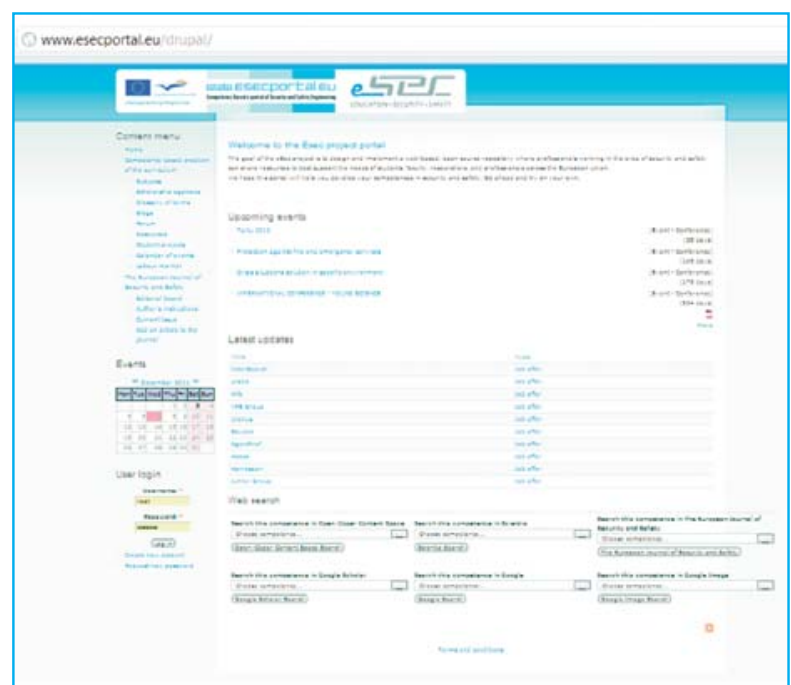

Fig. 2 Beta Version of the eSEC Portal

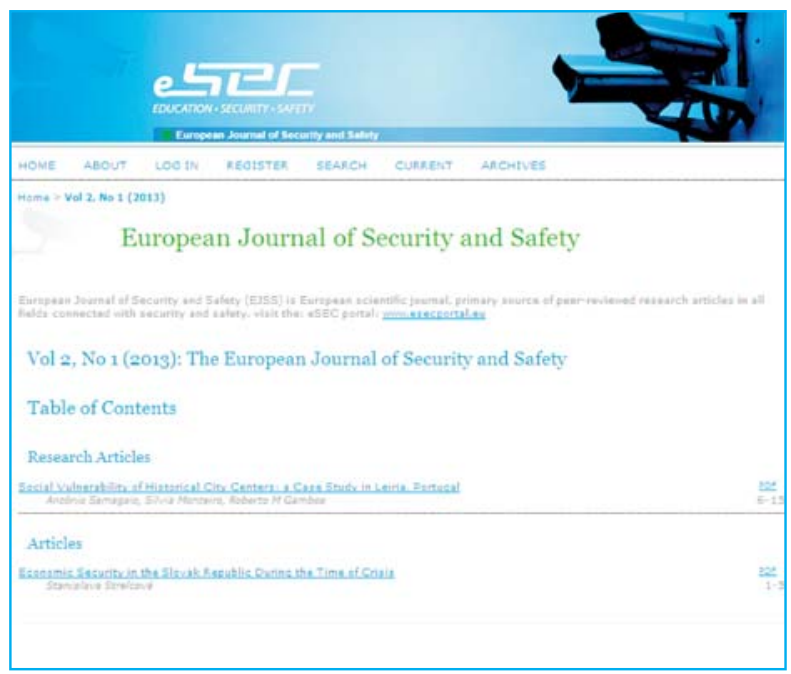

Fig. 4 eSEC Journal - European Journal of Security and Safety

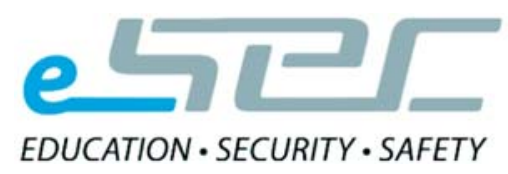

Fig. 5 eSEC Portal Logo

http://www.esecportal.eu/journal/

2010, which brought together 157 participants from 7 European countries (Czech Republic, Poland, Slovakia, Slovenia, Portugal, Ukraine, Russia).
Academic papers related to eSEC presented at conferences:

- Best Practices conference of eSEC portal project in March 2010 , 
- ISCRAM conference 2010 presented the eSEC project May 2010,

- International Conference on Computer Simulation in Risk Analysis and Hazard Mitigation, Algarve, Portugal in September 2010

- Several papers were presented during the conference Policing in Central and Eastern Europe in Slovenia.

Participation in these events allowed the consortium to obtain very useful feedback for development of the portal and its data content, and contacts for future cooperation.

The project consortium also participated in the following events:

- ITEC - Defence Training and Simulation Conference and Exhibition, London, May 2010,

- Conference Crisis Situations Solutions in Specific Environment, Slovakia, June 2010,

- Conference Open Source Systems for Education, Research and IT 2010, Slovakia, July 2010.

The mentioned Best Practices conference and several workshops (one in Slovakia, security and safety engineering within defined countries in Europe, in October 2010; and two in Portugal, April 2010 Civil Protection, prevention and society and November $2010 \mathrm{Tec}$ nicos de Proteccao Civil - Presente e Futuro) were prepared to receive not only the best practices, but also to increase the discussion for future directions for the project development and the preparation of the portal. At that stage the Glossary of Terms within 12 fields of security was finalised, which were also the 12 main fields of the portal:

- Economic Security,

- Energy Security,

- Environmental Security,

- Fire Protection,

- Industrial Security,

- Information Security,

- International Security,

- Civil Protection,

- Occupational and Health Safety,

- Protection of Persons and Property/ Private Security,

- Public Security,

- Transport Infrastructure Security.

A key document was also prepared, the Analysis Study (for more see [6]), which included analyses of the environment in individual regions, analysed by partner organisations of the eSEC project focused on the competences required by practice and academic society in the field of security and safety. A part of that document was the analysis of potential eSEC users' structure and their requirements, the structure and representation of expected target groups the portal users: students, teachers, academics, and professionals.

The document provided analysis of requirements for interactivity, user-friendly extremity, graphical surroundings and multimodality of eSEC portal's modules in relation to the expected target groups' skills. The document included analysis of eSEC portal's modules content based on required competences and the users' structure, which defined the need of individual modules focused on the identified 12 fields of security. In the conclusion of this document there were defined basic security and safety competencies within the fields according to Best Practices Conference of eSEC, the questionnaire of the Analysis Study and also formal and informal discussions during project implementation, with support of several communication channels.

Once the portal was launched the project consortium achieved its most important goal: to create the initial portal content which was hoped to bring wider community attention and thus lead to sustainability of the eSEC portal in the future. The project partners attempted to the maximal possible extent to create initial content which was as complete as possible (see Table 1).

The eSEC portal was also disseminated in several workshops, conferences and exhibitions organised by the consortium or where the partners were present, in the Check Republic, France, Germany, Ireland, Italy, Portugal, Russia, Slovakia, Slovenia, UK, ...

\section{Contribution to EU policies}

The eSEC project contributes to addressing the following EU policies:

1. The development of the high-quality life-long education and it supports high performance efficiency, innovations at the European dimension in the systems and procedures in the area of security and safety especially through an open access system that allows academics and professionals for accessing, creating and modifying broad information on different aspects of security and safety.

2. The eSEC project supports the European space of the life-long education on basis of linking the education of the European Professional community in the area of security and safety. In the framework of the portal it offers a space for linking educational institutions with practitioners from industry and government. The portal offers information from the area of security and safety to all stakeholders without any restriction.

3. The eSEC project through its key output - the eSEC portal contributes to disseminating information about relevant opportunities for the life-long education which are available throughout the member states, in particular on the basis of the modules created - e.g. Competency Based Creation of the Curriculum and Scholarships Agencies.

4. The eSEC project helps to support creativity, competitiveness, employment and development of the entrepreneurial spirit based on creating an environment that supports achieving competences in the area of security and safety both directly through the resources available at the portal and indirectly through the advisory process. Making the Competency Based Creation of the Curriculum aimed at particular competences, information about the scholarships abroad as well as the job offers in the area of security and safety where the employer requires certain competences from the student belong to the area of consultancy. The project increases the chance of finding a job by the portal users as it directly links competences required by employ- 


\begin{tabular}{|c|c|c|c|}
\hline \multirow{4}{*}{$\begin{array}{l}\text { eSEC portal content } \\
\text { Subjects }\end{array}$} & \multirow{4}{*}{$\begin{array}{l}\text { Description } \\
\text { The module is designed to publish subjects and study programmes } \\
\text { focused on various aspects of security and safety. }\end{array}$} & \multicolumn{2}{|l|}{ Figures } \\
\hline & & Subject & $>2630$ \\
\hline & & Country & $>26$ \\
\hline & & Universities & $>174$ \\
\hline $\begin{array}{l}\text { Scholarship } \\
\text { Agencies }\end{array}$ & $\begin{array}{l}\text { This module is designed to provide information about scholarship pro- } \\
\text { grammes and grant opportunities. }\end{array}$ & Organisations & $>150$ \\
\hline Glossary of Terms & $\begin{array}{l}\text { The Glossary of Terms is an easy way to browse an electronic } \\
\text { dictionary of terms in the twelve defined fields of security and safety. }\end{array}$ & Terms & $>500$ \\
\hline Resources & $\begin{array}{l}\text { This module is focused on innovative methods in education supporting } \\
\text { creativity and active approach of users to education and trainings in } \\
\text { the field of security and safety. It enables the user to access audio- } \\
\text { visual presentations from lectures, excursions, practical workshops, and } \\
\text { other sources. }\end{array}$ & $\begin{array}{l}\text { Audio-visual presentations from lectures, } \\
\text { excursions, practical workshops and } \\
\text { other sources }\end{array}$ & $>920$ \\
\hline Student Projects & $\begin{array}{l}\text { In this module view, compare, or publish students' works, which have } \\
\text { gained a prominent position in students competitions focused on } \\
\text { research and development activities within partners universities. }\end{array}$ & Student Projects & $>190$ \\
\hline Calendar of Events & $\begin{array}{l}\text { The module provides information about upcoming events within the } \\
\text { field of security and safety. }\end{array}$ & Upcoming events & $>200$ \\
\hline \multirow[t]{2}{*}{ Labour Market } & \multirow{2}{*}{$\begin{array}{l}\text { The module lists job offers in the field of security and safety within the } \\
\text { EU along with the functionality to publish professional CVs of the job } \\
\text { applicants. }\end{array}$} & Job offers & $>300$ \\
\hline & & Employee's offers & $>40$ \\
\hline $\begin{array}{l}\text { The European } \\
\text { Journal of Security } \\
\text { and Safety }\end{array}$ & $\begin{array}{l}\text { European Journal of Security and Safety (EJSS) is European scientific } \\
\text { journal, a source of peer-reviewed research articles in all fields related } \\
\text { to security and safety. }\end{array}$ & Articles & $>2$ \\
\hline References & Official support letters of eSEC portal from stakeholders. & Certificates & $>5$ \\
\hline
\end{tabular}

ers and those competences the student can acquire using the portal.

5. The eSEC project contributes to increasing popularity of the life-long education for people of all age categories through the free access to a great number of scientific and professional information from the area of security and safety.

6. The eSEC project supports collaboration and contributes to the quality of education and professional training in the area of security and safety in the EU. It is achieved through enabling collaboration between educational institutions and professionals in the EU.

The eSEC project contributes to fulfilling the following EU objectives:

1. The eSEC project supports the personal development of the eSEC portal users. It increases their chance to find a job and the participation in the European labour market based directly on providing the educational resources published at the eSEC portal and indirectly by providing information where and how the related competences can be gained and implemented.

2. The eSEC project is intended to increase mobility for the university students in the area of security and safety. With the use of the Mobility module, the students can learn about opportunities to study abroad.
3. The eSEC project increases and improves the collaboration between educational institutions, industry, government and public sector and other relevant organisations in whole Europe in the area of security and safety. This collaboration should be increased by sharing information through the portal and by exchange of students between universities.

The eSEC project contributes to fulfilling the following EU priorities:

1. The eSEC project supports the education and development of the teachers' skills through the eSEC portal that enables effective use of their time. The portal offers useful information and resources related to various areas of security and safety and it creates a platform for scientific collaboration, but also addressing practical problems from these areas.

2. The eSEC project contributes also to the development of the professional skills based on the market demand by linking the practitioners with educational institutions. The eSEC portal facilitates the flow of ideas between the professionals and the academia and naturally building bridges between these two communities, encouraging the practitioners to develop their skill sets and making the teachers and students aware of the current market requirements leading to more agile professional workforce. 


\section{Conclusion}

In this paper we discussed the portal for sharing information knowledge in field of security and safety that is intended for students, teachers and professionals. Among the benefits of the portal are: the centralisation of multiple resources at a single location, facilitating information and knowledge sharing, evaluation of published articles, advertising and promoting seminars and conferences, creating a common place for blogs related to security and safety, publishing student works, etc. It allows for searching information about scholarships, internships and possible work vacancies in fields of security and safety. These phenomena are more discussed within [7] and [8]. Another contribution of the eSEC portal is the specialised glossary of the security, safety and crisis management terms, with interactive search in six languages.

At a more abstract level, the eSEC-portal is intended to bridge the practitioners' community with educational institutions. It does so at the regional level but as well throughout all EU countries For the future it is expected that the reach of the portal will be beyond the EU and should cover the rest of the world. The eSECportal has become a centralised source of information in the field of security and with the intention to respond quickly to labour market demands through linking interested industries and agencies with current and prospect students. The development of the eSECportal is intended to contribute to increased participation in the lifelong education of people of all age categories by allowing access to information for all registered users regardless of the age and socio-economic background, in accordance with the rules for web application creation with the support of people with specific needs (also recommended to see [9], [10], [11], [12] and [13]).

A multilateral project eSEC - Competency Based e-portal of Security and Safety Engineering was submitted within the framework of Erasmus (Modernisation of Higher Education) and was focused on supranational cooperation among educational institutions and professionals, in the field of security and safety in the EU.
The official launch of the eSEC portal was on May, 30, 2012 at the Dissemination Conference of eSEC Portal, at the University of Zilina, in Zilina, Slovakia and the official opening on September 12, 2012 in Paris, France, at the last partnership meeting during the duration of the project.

The plans for the Future of the eSEC portal:

- encouraging involving the greatest possible number of stakeholders,

- keeping in contact with regular stakeholders' activities which should ensure that the eSEC portal content is regularly up-to-date,

- regular updating of the existing content and uploading of the new content,

- adding new modules based on the users' requirements (e.g. connection to the social networks, new e-learning tools, etc.),

- connecting the eSEC portal to other portals, networks and consortiums dealing with the issues of security and safety,

- encouraging involving the users on the creation of content, not only the partner institutions of the original project, but also the cooperating institutions of the individual project partners and other institutions, individual students, teachers or professionals,

- extending the collaboration with the partner institutions,

- addressing potential supporters, partners and sponsors.

The project consortium believes that the eSEC-portal will become an established and well known Internet portal in security and safety education, fulfilling the main objectives of the project.

\section{Acknowledgments}

This paper is a part of the Competency Based e-portal of Security and Safety Engineering project - eSEC - number: 502092LLP-1-2009-1-SK-ERASMUS-EMHE, funded by the European Commission with support from the Education, Audiovisual and Culture Executive Agency (EACEA) and reflects only the views of the authors.

This document reflects the views only of the authors, and the European Commission cannot be held responsible for any use which may be made of the information contained therein.

\section{References}

[1] CAPAY, M., TOMANOVA, J.: E-learning Support for Computer Graphics Teaching and Testing, Proc. of $9^{\text {th }}$ WSEAS Intern. Conference on Telecommunications and Informatics, pp. 117-121, 2010.

[2] JASEK, R., BENDA, R., VALA, V., SARGA, L: Launching Distributed Denial of Service Attacks by Network Protocol Exploitation, Proc. of Recent Researches in Applied Informatics, pp. 210-216, 2011.

[3] MIKA, V.: Personality and Competencies of Crisis Managers. Zbornik z medzinarodnej vedeckej konferencie Global Business \& Economic Development. New Jersey : Montclair State University, p. 135-142, 2001.

[4] KORMANCOVA, G.: Softverova podpora projektoveho riadenia / Software Support of Project Management, On-line journal: ManaZment v teorii a praxi, vol. 6, Nr. 1, 2010, ISSN 1336-7137; On-line dostupny na : http://casopisy.euke.sk/mtp/clanky/1-2010/mtp12010.pdf.

[5] SPIRCOVA, I., SULGAN, M.: Nove informacne technologie / New Infotechnologies (in Slovak), Proc. of conference Globalizacia a jej socialno-ekonomicke dosledky / Globalization and its Social and Economical Aspects, EDIS - ZU Zilina, 2004, ISBN-808070-311-6. 


\section{COMMNICOIIONS}

[6] Study analysis, [on line]. [cit. 2009-12-29], Available at: http://fsi.uniza.sk/kkm/esec/ study_analysis.pdf.

[7] HOLLA, K.: Dealing with Key terms in Risk analysis and Phenomenon of uncertainty in this process, Communications - Scientific Letters of the University of Zilina, vol. 9, No. 4, p. 59-61, 2007, ISSN 1335-4205.

[8] ZANICKA HOLLA, K., MORICOVA, V.: Human Factor Position in Rise and Demonstration of Accidents, Communications Scientific Letters of the University of Zilina, vol. 13, No. 2, pp. 49-52, 2011, ISSN 1335-4205.

[9] VELAS, A.: Poistovnictvo pre bezpecnostnych manazerov / Insurance for Security Managers (in Slovak), Zilina: EDIS - ZU, Zilina, 2009, ISBN 978-80-554-0149-2.

[10] SMRCKA, L.: Economic Harm of Promoting Photovoltaics, Intern. J. of Mathematical Models and Methods in Applied Sciences, 5 (4), pp. 813-821, 2011.

[11] MALINDZAKOVA, M.: Significance Evaluation of Environmental Aspects. Communications - Scientific Letters of the University of Zilina, vol. 13, No. 3, 2011, pp. 48-51, 2011, ISSN 1335-4205.

[12] SIMAK, L.: Increasing the Security Level in the Slovak Republic, Communications - Scientific Letters of the University of Zilina, vol. 10, No. 2, 2008, pp. 67-71

[13] SVENTEKOVA, E., DVORAK, Z., Human Activity as a Risk in Railway Transport, Transport Means - Proc. of the Intern. Conference, 2011, pp. 50-53. 